Bisset, K. A. \& Hale, C. M. F. (1953). J. gen. Microbiol. 8, 442-448.

\title{
The Cytology and Life-cycle of Azotobacter chroococcum
}

\author{
By K. A. BISSET ANd C. M. F. HALE \\ Department of Bacteriology, University of Birmingham
}

SUMMARY: Azotobacter chroococcum exists in two cytologically distinct vegetative forms. In one the appearance is that of a typical bacterial resting cell, with a large vesicular nucleus. In the other the cytoplasm appears homogeneously vacuolated and refractive; this is correlated with a high lipid content. Gonidia of two types are produced from the nucleated cells. The more common are tiny bacilli with polar flagella; these are released from the lumen of the mother cell and reproduce by fission. Larger gonidia, resembling miniature vegetative cells, develop within the mother cell, which becomes greatly elongated. These large gonidia do not appear to divide but grow directly into vegetative cells. Mother cells of both kinds may be Grampositive.

The fact that species of Azotobacter possess complex life cycles has been recognized for a relatively long time (Jones, 1920 ; Löhnis, 1921). Several points remain to be clarified, however, notably the relationships of the different growth forms observable in typical vegetative cultures to the formation of gonidia, the nature of the gonidial granules and the importance of 'symplasms'. In the present study the cytochemistry of the two major growth forms was studied in some detail and the mode of formation of the gonidia observed. The problems of vegetative cell division and the formation and germination of cysts, which have been fully described by Pochon, Tchan \& Wang (1948), were not approached on this occasion.

\section{METHODS}

Six strains with the characters of Azotobacter chroococcum were isolated from moistened soil plates, upon which they formed brownish mucoid colonies after about a week at room temperature. For cytological purposes the strains were grown either in tuberculin flasks in fluid medium, upon the surface of which a tough pellicle was formed, or upon a similar medium solidified with $2 \%$ agar. The composition of the medium was: $1 \%$ mannitol; $0.05 \% \mathrm{~K}_{2} \mathrm{HPO}_{4} ; \mathbf{0 . 0 2} \%$ $\mathrm{MgSO}_{4} \cdot 7 \mathrm{H}_{2} \mathrm{O} ; 0.02 \% \mathrm{NaCl}$; traces of manganese sulphate and ferric chloride; in tap water.

A wide variety of methods was used to stain these organisms. Good results were always easier to obtain when the cells were first defatted with xylene for about 5 min. at room temperature. The xylene was removed with $75 \%$ ethanol. Other solvents, such as ether, acetone and ethanol, even at boilingpoint, were almost without effect.

The classical $\mathrm{HCl}$ Giemsa technique was unsatisfactory with vegetative $A$. chroococcum, and although the nuclear structures had previously been found to stain well with the methylene blue eosin technique (Bisset, 1948) this method was avoided, as its results were entirely unpredictable. Various agents were employed instead of $\mathrm{N}-\mathrm{HCl}$ in the initial 'hydrolysis' process. The most 
successful were mild alkalis in $1 \%$ solution; lithium carbonate, sodium sulphate, sodium carbonate and magnesium sulphate produced comparable but not identical results. Nitric acid was also employed. After these treatments the cells were stained with Giemsa, thionin or crystal violet. The $\mathrm{HCl}$ Giemsa technique was found to be very successful with gonidial forms.

Lipids were demonstrated by the Ziehl-Neelsen technique and by a modification of this method in which differentiation is conducted in a saturated solution of picric acid in $\mathbf{7 5} \%$ ethanol. Lipids were also stained by Sudan IV and by a $10 \%$ solution of sulphuric acid in acetic anhydride, which gave a transient pale violet colour; a similar result was given by $5 \%$ trichloroacetic acid.

Useful results were also obtained by the Gram method and by basic fuchsin alone, as well as by tannic acid violet for cell walls. Gold-shadowed electron micrographs were made to observe the arrangement of flagella in both vegetative cells and gonidia. These results were confirmed by silver-impregnation methods of flagella staining. Phase-contrast microscopy was also employed. No special method was used to demonstrate the polysaccharide capsule, which was not studied.

The cytochemical studies of vegetative cells are illustrated exclusively by drawings because, whereas they do not embody any original observations upon the morphology of $\boldsymbol{A}$. chroococcum, the synthesis of information obtained from a very large number of stained preparations is most clearly presented in this manner. Both drawings and photomicrographs of the gonidial stages are presented.

\section{OBSERVATIONS}

Cultures of $\boldsymbol{A}$. chroococcum grow very slowly for several months. In very young cultures, less than a week old, many cells have a curious appearance, sometimes described as 'vacuolated cytoplasm', in which the cell contents appear as though bubbly, full of refractile bodies like glass beads. A proportion of cells at any stage always show the typical vesicular nucleus, with a larger or smaller number of peripheral chromatinic granules. After about 10 days in culture, these forms tend to predominate until in the later stages, after several weeks or even months, the entire culture is transformed into tiny bacilli from which typical $A$. chroococcum are regenerated on subculture. The formation of gonidia is greatly accelerated in fluid medium.

The cytological staining of the nucleated forms was curiously variable and is indicated by the drawings of Figs. 1-3. When treated with a mild alkali and stained with Giemsa the entire nucleus either stained uniformly or exhibited a negative staining of the eccentric granule which, typical of bacterial resting nuclei (Bisset, 1950), occupied one or both poles of the nucleus (Fig. 1). Similar preparations stained with thionin after preliminary treatment with either alkali or acid showed the same granules staining much more strongly than the remainder of the nucleus, which appeared as an empty vesicle (Figs. 2, 3). Although, as stated above, these forms appeared to have a high lipid content, as indicated by the greater affinity of defatted material for aqueous dyes, they did not stain with Sudan IV or acetic anhydride. 
By contrast, the vacuolated cells (Figs. 4-7) stained well with such lipidindicating reagents. Young cultures examined by phase-contrast microscopy showed clearly that the difference between the nucleated and vacuolated cells was not due to staining artefacts but could be seen in living material (Fig. 4a,b). It is tempting to attempt to correlate the appearance of these cells, which seem to be filled with globules, with the initiation of gonidium production. There appears, however, to be no connexion; the vacuolated cells are commonest in the younger stages of culture and are remarkable only for this very high lipid content. When defatted and stained with nitric acid thionin, only the outlines of the globules appeared to stain (Fig. 5). The complementary effect was seen in preparations stained by Ziehl-Neelsen, which showed the globules to be distinctly acid-fast (Fig. 6). As a control, mixed preparations of $A$. chroococcum and Rhizobium sp. were stained; the latter showed no acid-fast granules. The characteristic appearance of these cells was less well seen when stained by Sudan IV or acetic anhydride (Fig. 7) as the fat globules appeared to be displaced towards the periphery of the cell. This may well have been a physical effect due to solution of the lipids. The exact nature of the lipid in $A$. chroo-

Fig. 1. Nucleated cells stained by lithium carbonate and Giemsa.

Fig. 2. As Fig. 1, by magnesium sulphate and thionin.

Fig. 3. As Fig. 1, by nitric acid and thionin. Comparison of Fig. 1 with Figs. 2 and 3 shows negative and positive staining respectively of the large perinuclear granules.

Fig. 4. Phase-contrast appearances of vacuolated cells $a$ and nucleated cells $b$.

Fig. 5. Vacuolated cells stained by nitric acid and thionin. The outlines of the globules are stained.

Figs. 6, 7. As Fig. 5, stained for lipids by Ziehl-Neelsen (Fig. 6), Sudan IV (Fig. 7). In the former case the acid-fast material corresponds closely to the refractive globules seen in unstained cells, but the Sudan IV demonstrates material nearer the periphery, and possibly displaced by partial solution.

Fig. 8. Typical appearance of small gonidia released from mother cells whose broken cell walls are also shown. Stained Gram and appearing Gram-negative. Those still enclosed in the mother cell frequently appear Gram-positive.

Fig. 9. Alternative appearances seen in Gram-stained mother cells. In $a$ the large type of gonidia are seen at two different stages of maturation. In $b$ a relatively mature, elongated mother cell of this type is shown, by comparison with $c$, in which the postulated process of elimination of a proportion of the original, large number of granules (as in the right-hand cell of $a$ ) is proceeding. All these stages are Gram-negative. By contrast the mother cell $d$ is filled with undifferentiable Gram-positive material, presumably immature gonidia.

Fig. 10. Free gonidia of the small type, which when released are invariably Gram-negative, as contrasted with the later stages of formation of the large gonidia, which are still contained in the now greatly elongated mother-cell, and stain with a Gram-positive cortex. With Giemsa, these chains of large gonidia stain deep red, the small gonidia, pale blue.

Figs. 11, 12. Cytological appearances of the small gonidia; rod-like and coccal forms respectively, by $\mathrm{HCl}$ Giemsa. The typical bacterial nucleoids are seen.

Figs. 13, 14. Flagellation of vegetative cells and small gonidia respectively, from electron micrographs and silver impregnation preparations. The mature cells have irregularly peritrichous flagellation; the gonidia, a tuft of up to four or five polar flagella. The arrangement of the flagella at the poles of the double cell is an indication of normal cell division. 


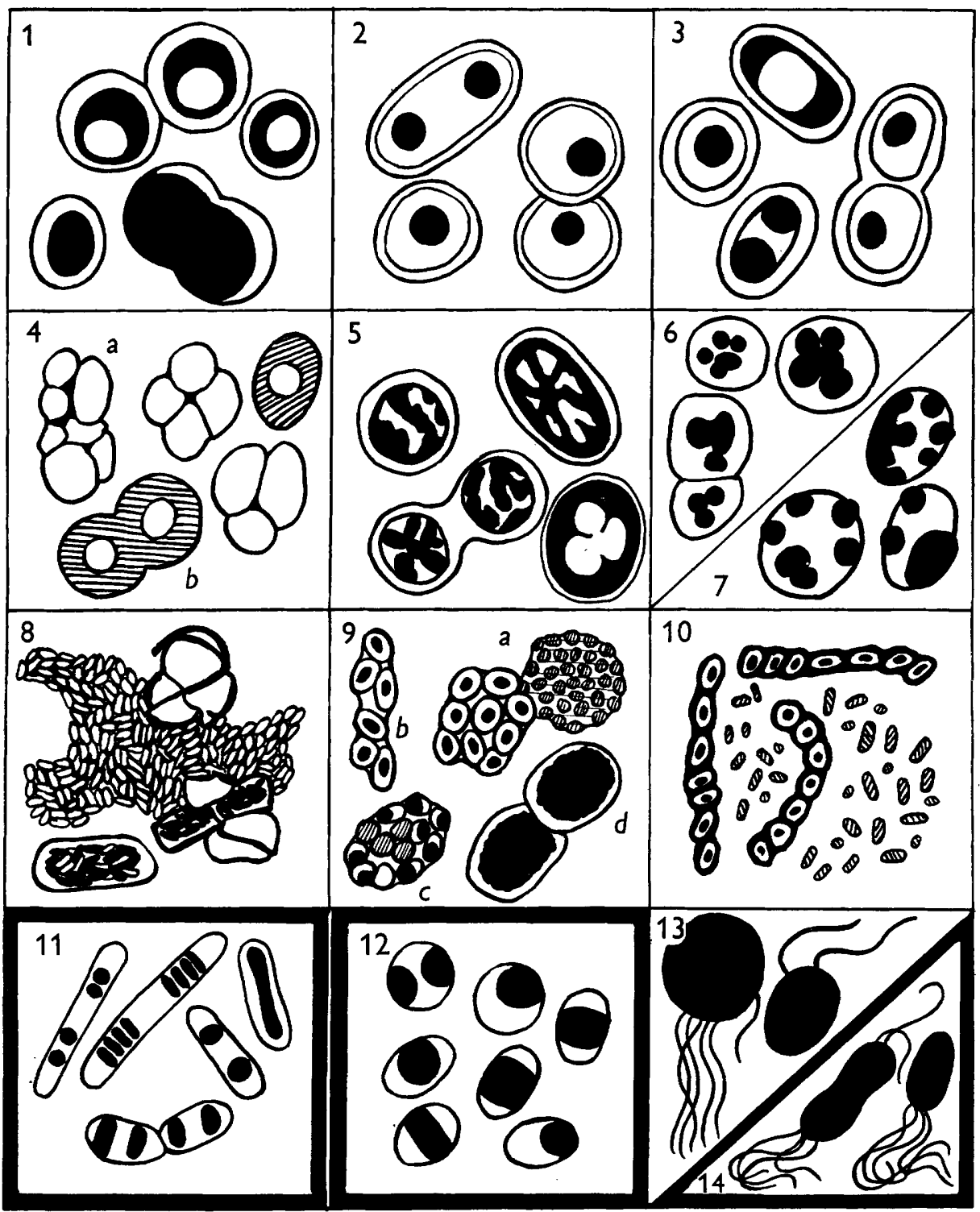

For legends see facing page

Figs. 1-14. These are drawings from microscopic preparations, with the exception of Fig. 4, which is taken from a phase-contrast study of living material, and Figs. 13 and 14 which are stylized and are from observations on both microscopic preparations and electron micrographs. All are shown at a magnification of $\times 4000$, approximately, except Figs. 11, 12 and 14 (bordered by a heavy line), which are at $\times 15,000$, approximately. The capsules are not demonstrated. 
coccum is uncertain; Anderson (1948, p. 377) states that this species contains ergosterol, but since they appear to be acid-fast, and are more soluble in xylene than in ethanol, it is probable that the sterols indicated by the acetic anhydride reaction are constituents of wax-like compounds.

No sign of internal cell walls could be discerned in tannic-acid violet preparations, and it is considered that these do not occur, and that the 'vacuoles' are cytoplasmic.

Reproduction by gonidia was seen after a variable time, usually not less than 5 or 6 weeks, and cultures on solid medium did not always show the phenomenon. Curiously, it could often be initiated immediately by growth on nutrient agar containing fresh horse blood, but not boiled blood or serum. The reason for this effect is not known.

The characteristic appearance of gonidium production is shown in Fig. 8 and Pl. 1, fig. 1. Masses of tiny bacilli were seen, with the broken and empty cell walls of the mother cells, and others still packed with gonidia. Like the vegetative $\boldsymbol{A}$. chroococcum, the gonidia were for the most part Gram-negative, but while still enclosed in the mother cell, a large proportion were Gram-positive. In Figs. 9, 10 and Pl. 1, fig. 1, a second type of gonidium is illustrated; Fig. $9 a$ shows a double mother cell in which one half is occupied by small granules, apparently gonidia in the course of development, whereas the other half contains relatively large bodies exactly resembling miniature vegetative cells. Cells filled with these larger gonidia were frequently elongated in form (Fig. 9b). In Fig. 9c, however, the large gonidia are shown at an earlier stage of development, and here the cell retains its oval outline. The number is rather larger, but their appearance is variable, and some gonidia stain much less deeply and lack a defined nucleus. Since the mature mother cells of this type very rarely contained more than eight or nine gonidia, it appears that a proportion of these must degenerate to permit the development of the remainder. It is probable that the small granules seen in the right-hand portion of Fig. $9 a$ are in a still earlier stage of development into similar large gonidia, and are consequently much more numerous than in the left-hand portion. Cells containing masses of Gram-positive material, in which no structures could be discerned, were also seen (Fig. 9d), and Gram-positivity was shown by the large gonidia at a later stage of development (Fig. 10). These did not appear to be fully released from the mother cell, but the outline of each group of six or eight cells, comprising a 'brood', became more and more elongated until they formed chains, apparently cemented by a surface material which sometimes stained Gram-positive, and which was acidophilic, staining bright red with Giemsa, whereas the small gonidia stained blue and were Gram-negative. These large gonidia apparently developed directly into vegetative Azotobacter on subculture, and did not reproduce; nor did they possess any demonstrable flagella.

By contrast the small gonidia appeared to reproduce freely by fission, in the course of growth. Cytologically they were typical, small bacteria (Figs. 11, 12), and possessed the nuclear structures appropriate to their morphology, whether relatively long, slender rods with paired chromosomes, or shorter 
almost coccal forms with eccentric chromatinic granules (cf. Bisset, 1950). They were actively motile by tufts of from one to five flagella at the poles, in contrast to the rather irregularly peritrichous arrangement of full-grown, vegetative cells (Figs. 13, 14; Pl. 1, figs. 3, 4). On subculture these tiny rods either developed directly into vegetative forms or reproduced for some time in the form of Gram-negative rods resembling normal-sized Bacterium species. The large gonidia were by no means always present, and were invariably much less numerous than the small type.

The existence of 'symplasms' in the life cycle of Azotobacter spp. (Löhnis, 1921) is not confirmed by this study. Masses of gonidia of both types were frequently seen, and the presence of the relatively large nucleated cells within a group of tiny forms, so small as perhaps to be indistinguishable by the microscopic techniques of that date, may have given the impression of a mass of undifferentiated cytoplasm, which enclosed a number of nuclei (i.e. the large gonidia), especially if the peculiar mode of formation of the latter was not fully recognized (Pl. 1, fig. 2). It is not considered, however, that the existence of symplasms has been entirely disproved, although it certainly has not been confirmed.

\section{DISCUSSION}

The nucleated forms of vegetative $A$. chroococcum and the forms showing 'vacuolated cytoplasm' are not, as has been believed, varied appearances in similar cells produced by cytological techniques, but are distinctly different in their morphology and can be distinguished by phase-contrast microscopy of living material. The vacuolated forms appear to possess an even higher content than usual of lipid material, and are common in the early stages of culture. Despite the superficial resemblance between the refractile globules which cells of this type contain, and the gonidial granules with which mother cells become packed in the later stages of culture, there is no real connexion between the two appearances. In the nucleated stage it appears that the largest of the chromatinic granules on or near the periphery of the nucleus (Bisset, 1948) is cytochemically distinct from the remainder of the nucleoplasm, but no evidence of its nature is available.

Gonidial reproduction in this species comprises two different processes which differ fundamentally only in that whereas both probably begin in an identical manner, with the production in the mother cell of a large number of small gonidial granules, these may proceed either to the formation and release of an equivalent number of tiny rod-shaped gonidia with polar flagella, or alternatively the majority may be sacrificed to the formation of a much smaller number of relatively large gonidia which resemble miniature vegetative forms. This process is analogous to seed production in certain plants, where several fertilized ovules take part in the protection of the single one which is destined to reproduce. The small and large gonidia differ also in that the former reproduce by fission while the latter seem to be transformed directly into mature vegetative cells by a simple increase in size, are not immediately released but remain in their original groups still enclosed in the mother-cell 
envelopes, and become elongated to form short chains surrounded by a cortex which frequently stains Gram-positive. The masses of developing small (or undifferentiated) gonidia within the mother cells may also stain Gram-positive for a short time before their disruption. In both cases this appearance is lost when the gonidia are released.

Whereas the large gonidia resemble the nucleated vegetative cells cytologically, the small gonidia are typical of small bacteria in this respect and are provided with a tuft of polar flagella. They are reminiscent of swarmers of Rhizobium spp. (Bisset \& Hale, 1951), but are rather less specialized, since these are released as spherical cells with a single flagellum and develop into small bacteria at a later stage of the life cycle.

The systematic position of $A$. chroococcum has often been the subject of dispute; it has been suggested that it more closely resembles the yeasts than the bacteria, but the occurrence of such typically bacterial stages in its life cycle, together with its possession of bacterial flagella makes its inclusion in the Eubacteriales as defined by Bisset (1952) almost indisputable.

\section{REFERENCES}

Anderson, C. G. (1948). An introduction to bacteriological chemistry. 2nd ed. Edinburgh: Livingstone.

Bisset, K. A. (1948). Observations upon the bacterial nucleus. J. Hyg., Camb. 46, 264.

BisseT, K. A. (1950). The cytology and life-history of bacteria. Edinburgh : Livingstone.

Bisset, K. A. (1952). Bacteria. Edinburgh: Livingstone.

Bisset, K. A. \& HALE, C. M. F. (1951). The production of swarmers in Rhizobium spp. J. gen. Microbiol. 5, 592.

Jones, D. H. (1920). Further studies on the growth-cycle of Azotobacter. J. Bact. 5, 325.

LöHNIS, F. (1921). Studies upon the life-cycles of bacteria. Mem. nat. Acad. Sci. $16,1$.

Pochon, J., Tchan, Y. T. \& Wang, T. L. (1948). Recherches sur le cycle morphologique et l'appareil nucléaire des Azotobacter. Ann. Inst. Pasteur, 74, 182.

\section{EXPLANATION OF PLATE}

Plate 1

Fig. 1. Azotobacter chroococcum; small gonidia and mother cells containing gonidia of large and small types at varying stages of maturation. Compare Figs. 8-10. Gram method; $\times 3000$.

Fig. 2. Azotobacter chroococcum; 'symplasm' showing large type of gonidia embedded in a mass of small gonidia and disrupted cell material. Gram method; $\times 3000$.

Figs. 3 and 4. Azotobacter chroococcum; small gonidia showing bacillary form and polar flagellation. Electron micrograph, gold-shadowed; $\times 16,000$. 
Journal of General Microbiology, Vol. 8, No. 3
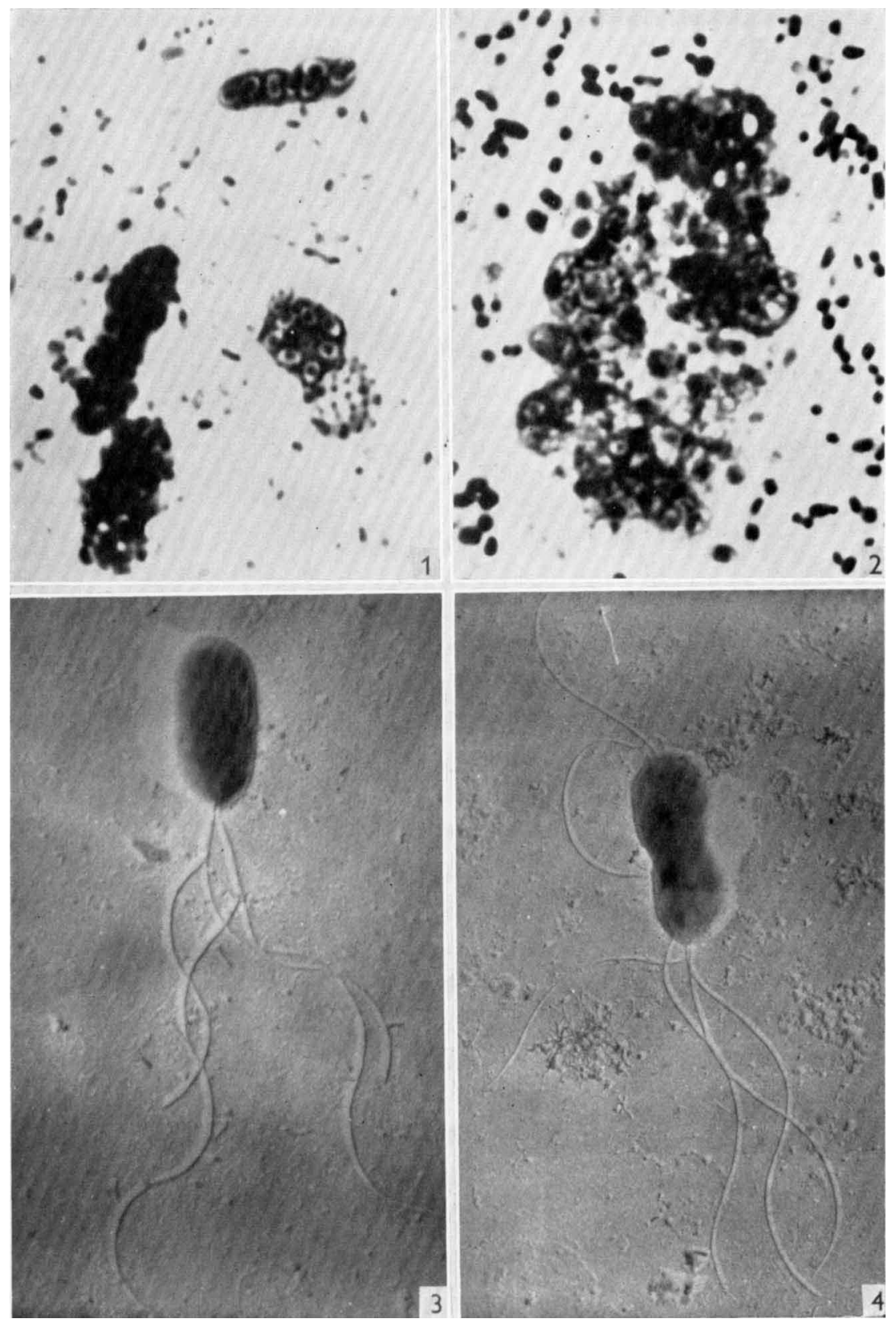

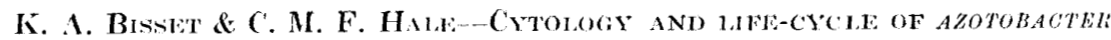
chioococezy. Plate 1 